\title{
The fire behaviour of multi-bay, two-way reinforced concrete slabs
}

\author{
P.J. Moss ${ }^{\mathrm{a}, 1}$, R.P. Dhakal ${ }^{\mathrm{a}}$, G. Wang ${ }^{\mathrm{b}}$ \& A.H. Buchanan ${ }^{\mathrm{a}}$ \\ ${ }^{a}$ Department of Civil Engineering, University of Canterbury, Private Bag 4800, Christchurch, New \\ Zealand \\ ${ }^{b}$ Arup Fire, 1 Nicholson St, Melbourne, Victoria 3000, Australia
}

\begin{abstract}
This paper describes numerical modelling of the fire behaviour of two-way reinforced concrete slabs in a multi-storey multi-bay building. The building is square, with three bays in each direction. The concrete slab is supported by a perimeter frame, four internal columns and no internal beams. It is assumed that all nine bays of the concrete slab at one level are subjected to fire from below. Two fires were used; the standard ISO834 fire for a 4 hour duration, and a parametric fire based on the ISO834 fire for one hour with the temperatures decaying to ambient in another two hours. The effects of the fires are described in relation to the redistribution of bending moments and the development of tension field action in the slab.
\end{abstract}

Keywords: fire resistance, reinforced concrete, flat slabs, continuity, SAFIR, membrane action

\section{Introduction}

The design of reinforced concrete slabs for fire resistance is usually based on prescriptive generic ratings that specify the minimum slab thicknesses and the required concrete cover to the reinforcing steel. These generic ratings have generally been based on standard fire resistance tests using furnaces which are not representative of real construction because they do not account for two-way action or the effects of axial restraint at the slab supports.

The fire resistance ratings of one-way restrained floor systems are generally higher than those for unrestrained floors because compressive restraint in the surrounding structure develops compressive membrane action in the slab, increasing the time to failure in standard tests [1]. Based on such test results, a simple hand method has been developed $[2,3]$ for calculating the fire resistance of slabs considering the effects of compressive membrane action. Several researchers [4-6] have found that the compressive membrane action is sensitive not only to the duration of fire exposure, the location of the restraint on the edges of slabs, and the arrangement of reinforcing bars in slabs, but also to the ratio of the span to the thickness of slabs.

Once large deflections occur, tensile membrane action can significantly increase the fire resistance of reinforced concrete slabs, especially two-way slabs. For ambient conditions, Park [7] developed a theory to determine the load carrying capacity of

${ }^{1}$ Corresponding author. Tel.: +64 3364 2245; fax: +64 33642758

Email Address: peter.moss@canterbury.ac.nz 
reinforced concrete slabs at large deflections by considering the tensile membrane action. Park and Gamble [8] describe how significant tensile membrane action in slabs at ambient temperatures can occur if the movement of the edges of slabs is restrained. The tensile membrane action of slabs is not fully understood at elevated temperatures. However, based on tests [9-12], a design method for determining the ultimate load carrying capacity of two-way slabs has been developed by considering the effects of tensile membrane enhancement at elevated temperatures. The tensile membrane action in slabs is sensitive to the duration of fire exposure, the restraint of the edges of slabs, and the arrangement of reinforcing bars in the slabs.

Redistribution of bending moments after development of plastic hinges can give significant advantages in the fire design of continuous structural members [1]. This also applies to slabs. When the slab is exposed to fire from below, the top reinforcing bars remain cool with no loss of strength whereas the bottom bars have reduced yield strength due to elevated temperatures. This allows redistribution of bending moments to occur, with the negative moment near the supports becoming much larger than the positive moment near mid-span. 3-D analyses of reinforced concrete floor systems exposed to fire can be performed using special purpose computer programs, such as SAFIR [13]. The design of reinforced concrete floor systems exposed to fire is more complicated and difficult than normal design of structural members because thermal bowing, lateral deformations and resulting P- $\Delta$ effects must be considered.

Many different fire exposures are also possible. A parametric fire represents actual fires better than a standard fire because of unexpected structural behaviour in the decay phase. In addition, the size and duration of a fire depends on the combination of fuel load, ventilation openings, and the wall lining materials [1], and a number of parametric fires can be chosen to represent a range of realistic fires from short hot fires to long cool fires. This study used one continuous standard fire and one parametric fire.

\section{Structural Details/Design}

This paper investigates the fire performance of a two-way reinforced concrete slab subjected to fire over its whole area. The slab being analysed is the lowest suspended floor of a multi-storey building, with $3.6 \mathrm{~m}$ inter storey height. The building is three bays by three bays in plan, with columns at $6 \mathrm{~m}$ centres both ways, so the slab comprises nine $6 \mathrm{~m}$ square panels, $0.2 \mathrm{~m}$ thick. The slab is supported on a perimeter frame of beams $0.25 \mathrm{~m}$ wide by $0.5 \mathrm{~m}$ deep spanning between columns at $6 \mathrm{~m}$ centres. There are four internal columns and no internal beams. All columns are $0.5 \mathrm{~m}$ square.

The flat slab was designed according to the direct design method of Section 13.6 in ACI 318R-89 [14]. The X-direction reinforcing bars were placed on the top of the Ydirection reinforcing bars. Details of the reinforcing are given by Wang [15]. The reinforcement in all elements had a minimum concrete cover of $30 \mathrm{~mm}$.

The uniformly distributed loads on the slab are:
Self weight + superimposed dead load, $G$
$5.3 \mathrm{kN} / \mathrm{m}^{2}$
Live load, $Q$
$4.0 \mathrm{kN} / \mathrm{m}^{2}$
Ultimate load, $1.2 G+1.6 Q$
Fire load ${ }^{[16,17]}, 1.0 G+0.4 Q$
$12.8 \mathrm{kN} / \mathrm{m}^{2}$
$6.9 \mathrm{kN} / \mathrm{m}^{2}$ 


\section{Analytical Modelling}

\subsection{Fire exposure}

The behaviour of the slab is compared for two different fire exposures; the standard ISO fire [18] for four hours and a parametric fire based on the ISO fire for one hour with temperatures decaying back to ambient during the following two hours as shown in Figure 1. The fire is assumed to occur on the ground floor and therefore impacts the underside of the lowest suspended floor slab. The fire temperatures were taken to be identical over the entire slab area, so the temperatures in the shell elements varied only through the thickness. The perimeter beam was exposed to fire only on the bottom and inner surfaces. The columns were not exposed to the fire and remained at ambient temperature.

The distribution of temperatures through the depth of the $0.2 \mathrm{~m}$ thick slab exposed to an ISO 834 standard fire without a decay phase is shown in Figure 2 (top). It can be seen that the temperature $30 \mathrm{~mm}$ above the bottom of the slab (i.e. at the level of the bottom reinforcement) increased from $20^{\circ} \mathrm{C}$ at 1 minute to $700^{\circ} \mathrm{C}$ at 180 minutes and continuously increased to $775^{\circ} \mathrm{C}$ at 240 minutes when the simulation was stopped. Figure 1 and Figure 2 (bottom) show the distribution of temperatures in the slab when exposed to the same fire, but with a decay phase. It can be seen that the temperature $30 \mathrm{~mm}$ above the bottom of the slab increased from $20^{\circ} \mathrm{C}$ at 1 minute to $450^{\circ} \mathrm{C}$ at 90 minutes, a maximum of $456^{\circ} \mathrm{C}$ at 84 minutes, and then declined to $160^{\circ} \mathrm{C}$ after 240 minutes. While temperatures in the bottom of the slab declined significantly during the decay phase of the fire, the temperatures in the upper part of the slab continued to increase slightly on account of the thermal gradient through the slab thickness.

\subsection{Material properties and modelling}

The concrete was assumed to be of siliceous aggregate, with a compressive strength of $30 \mathrm{MPa}$. The elastic modulus at ambient temperature was taken to be $18 \mathrm{GPa}$. The reinforcing steel was assumed to have a yield strength of $430 \mathrm{MPa}$ and an elastic modulus of $210 \mathrm{GPa}$. The material properties for both concrete and steel vary with temperature according to EC2 part 1.2 [19].

The computer program SAFIR [13] from the University of Liège, Belgium, was used to carry out the analyses. SAFIR has been used extensively to simulate the fire behaviour of reinforced concrete slabs and its applicability has been verified experimentally [20]. The layers of reinforcing bars in the slab are treated as being smeared across the shell element and show uniaxial behaviour. The concrete model allows for isotropic thermal strain in the concrete and uses a temperature-dependent Von Mises plane stress associated plasticity model to define the failure surface while a Rankine surface is used in tension. Hardening is isotropic with different parameters being used to define the compression and tension surfaces. The hardening curve in tension is quadratic up to the strain of the tensile strength, then cubic in the descending branch. However, as recommended by the developers of SAFIR [21], the analyses were carried out assuming that the concrete had zero tensile strength. This also helps to put a conservative demand on reinforcing bars to cater for tensile membrane action which was found to be instrumental in holding the slab when it deforms in a catenary. As SAFIR is able to deal with a decaying fire, the material models are fully path-dependent and include proper unloading and reloading loops. The concrete follows a linear unloading path from compression to zero stress (as zero tensile strength is assigned for 
concrete) with a reduced stiffness (in comparison with the initial stiffness) whereas the reinforcement follows perfectly elasto-plastic loading-unloading-reloading path (i.e. the Bauschinger effect is not taken into account). Further details of the steel and concrete material models used in SAFIR are given by Talamona and Franssen [21].

The material models used in SAFIR can capture local failure modes such as crushing of concrete due to excessive compression and rupture of reinforcing bars due to excessive tension. Moreover, the reduction of material strength and stiffness with elevation in temperature has also been accounted for in these models. On the other hand, SAFIR does have some limitations. Spalling of the concrete cannot be modelled in SAFIR, and full composite action between the concrete and the reinforcing steel is assumed, with no slip between these two materials. Shear failure of the beam and shell elements cannot be determined. Moisture migration cannot be modelled in the thermal analysis but the effect of moisture on the temperature distributions is accounted for by using appropriate thermal properties.

\subsection{Structural analysis}

Using symmetry, only one quarter of the structure was modelled by SAFIR. The columns were taken as fully fixed at the base, and restrained against all but vertical movement at the top. The columns above and below the fire-exposed floor were discretized into nine beam elements. The beam members were discretized using a number of $0.3 \mathrm{~m}$ long beam elements. The concrete slab was modelled using $0.3 \mathrm{~m} \mathrm{x}$ $0.3 \mathrm{~m}$ square shell elements. Details of the shell finite elements in SAFIR are given by Talamona and Franssen [21].

\section{Results for the ISO Fire Exposure}

The top view of a quarter of the nine-bay flat slab is shown in Figure 3. For a convenient description of the behaviour of the slab, 16 points, 5 strips and 5 sections are defined. Points B2, B4, D2, and D4 are at the centroids of the columns, while point A1 is the central point of the nine-bay slab. Point A1 is also the absolute coordinate zero point. The strips along the X-direction are indicated by letters, whilst the sections along the Y-direction are indicated by numbers. Some terms which will be used in further discussions are also shown in Figure 3 as well (e.g. Edge Column-1, Beam-1).

\subsection{Vertical Displacements}

Figure 4 shows the vertical deflections of the slab at points A1, B1, C1, and D1. The deflection at point $\mathrm{D} 1$, which is a common point between the beam element and the shell element, was always very small because of the large flexural stiffness of the edge beams that were partially exposed to the fire. For the first 30 minutes, the deflections of points $\mathrm{A} 1, \mathrm{~B} 1$ and $\mathrm{C} 1$ were almost the same. After this time, the deflection of points $\mathrm{A} 1$ and $\mathrm{C} 1$ remote from the column strips exceeded that at point $\mathrm{B} 1$ between the columns because of redistribution of the bending moments in the slab. The largest deflection was at point A1, the central point of the nine-bay slab. The change in the shape of the deflection curves at 180 minutes occurred when part of the slab became a catenary, with loads being resisted mainly by tensile membrane action. That the slab becomes a catenary after $180 \mathrm{sec}$ can also be deduced from Figure 4 which shows that points A1, $\mathrm{B} 1$ and $\mathrm{C} 1$ move down very slowly and by exactly the same amount. This means that 
the slab does not deform in itself, but just deflects downward slowly as the reinforcing bars anchored to the side beam yield/elongate due to tensile membrane action.

Figure 5 shows the deflected shape of the slab after 180 minutes, where the vertical deflections of the strips of slab between the columns are less than in the central parts of the slab. The slab deformed as a 3-D catenary, hanging on the columns, the column strips, and the beams. At this stage, the stresses around the perimeter of interior columns are more severe than elsewhere. This is also obvious from the deflection profile shown in Figure 5. The curvature around the column perimeter is large, so the bottom layer of the slab will be in high compression and the top layer in high tension. This makes the column perimeters vulnerable to deterioration and thereby probably leads to punching of the columns through the slab. The material model is capable of capturing concrete crushing and the concrete is assumed as cracked from the very beginning as zero tensile strength is assigned for the concrete. Nevertheless, despite accounting for the deterioration of concrete in high compression, the analysed cases did not show enough deterioration of the column perimeters to trigger punching shear failure. Probably, collapse did not occur because the top reinforcing bars in the slab were anchored into the edge beams.

\subsection{Bending moments}

The sign convention for bending moments in this paper is that the bending moments are drawn on the tension side of the slab, with positive values representing hogging moments resisted by tensile stresses in the top reinforcing bars, and negative values representing sagging bending moments resisted by tensile stresses in the bottom reinforcing bars. Because the slab is symmetrical about both axes, only X-direction bending moments are presented. An analysis of the bending moments in the slab shows that the redistribution of bending moments is significantly affected by the arrangement of the top reinforcing bars in the slab, and this redistribution is one of the main factors affecting the fire endurance and preventing the collapse of the slab.

Figure 6 shows the distribution of X-direction bending moments along Strip A (i.e. along a slab centreline). The shaded parts in the graph are the column strips, whilst the unshaded parts are the middle strips. The lowest curve shows that at the beginning of fire exposure, the bending moments in the column strips are positive (hogging with tensile stresses in the top reinforcing bars) and negative in the middle strips (sagging with tensile stresses in the bottom reinforcing bars), as expected. As the temperature of the fire increases, redistribution of bending moments in the slab occurs, so that all the bending moments along the strip become positive, but still retaining roughly the original shape. The positive bending moments result from the slab attempting to undergo thermal bowing (due to the heated lower surface) but being unable to bow because of restraint provided by the internal columns. Another factor is that the negative flexural (sagging) capacity of the slab declines when the temperatures of the bottom reinforcing bars exceed $300^{\circ} \mathrm{C}$ and the yield strength of this steel starts to decrease.

Figure 7 shows the distribution of X-direction bending moments along Section 1, through the middle of the slab. This is not a normal bending moment diagram because it shows $\mathrm{X}$-direction bending moments plotted along the $\mathrm{Y}$-axis. The variation with time of the bending moments at the centre of each strip in Figure 7 is shown in Figure 8. It can be seen that the only place where there are significant negative moments is the centre of the column strip, and these steadily reduce in the first hour of fire exposure, 
becoming positive after 80 minutes. All the other bending moments in Figure 8 become positive in the first 15 or 20 minutes of fire exposure.

\subsection{Membrane forces}

Figure 9 shows the distribution of X-direction membrane forces along Section 1. Tensile membrane forces are positive. The membrane forces vary along the section because of the effects of restraint provided by the beams and columns. It can be seen that the distribution of membrane forces in the middle strips is much smoother than in the column strips. The variation of membrane forces with time is shown more clearly in Figure 10, where it can be seen that the forces in the column strip are tensile throughout the fire. In all other strips there is an increase in compressive forces during the first 30 minutes, followed by a reduction to zero after 60 minutes, then an increase in tensile forces following the same pattern as in the column strip.

\subsection{Horizontal Displacements}

Figure 11 shows the X-direction displacements at the column locations (points B2, B4, D2 and D4). It can be seen that the corner column and two edge columns moved outwards from the centre of the slab (negative value of horizontal displacements), whilst the middle column moved towards the centre of the slab (positive value). Comparing Figures 10 and 11 shows that in the first stage of the fire the outward horizontal displacements of the columns were mainly affected by the thermal expansion of the slab (increasing concrete forces) and the edge beams. As the vertical displacements of the slab became larger, compressive membrane forces dropped off and became tensile, as shown in Figure 10, followed by a reduction in the outward displacement of the exterior columns (Figure 11).

The outward movement of the corner column throughout the fire indicates that the horizontal movements of the corner column were dominated by thermal expansion of the slab.

The shape of the slab after 120 minutes of the fire is shown in Figure 12. The horizontal movements of the perimeter beams had a tendency to enhance the development of the tensile membrane forces in the slab and reduce the vertical deflections.

\section{Results for Parametric Fire Exposure with a Decay Phase}

The analysis using the parametric fire was only run for 200 minutes as this was approximately 30 minutes after the fire temperature had reduced to ambient.

\subsection{Vertical displacements}

Figure 13 shows the vertical deflections of the same points shown in Figure 4 . It can be seen that in the case of the parametric fire, the deflections remain reasonably constant after the fire starts to decay. The deflected shape of the slab after the fire temperature has decayed to ambient is shown in Figure 14 and has a similar form to that in the ISO fire (Figure 5).

\subsection{Bending moments}

The average bending moments in the strips along Section 1 are shown in Figure 15, with the values for the column strip in the ISO fire shown for comparison. By comparison 
with Figure 8, it can be seen that once the fire goes out, the bending moments in the strips change appreciably as the tendency for thermal bowing changes due to greatly reduced thermal gradient in the slab (Figure 2, bottom). The bending moments in most strips change from positive (hogging) to negative (sagging) after about 120 minutes. The bending moments in the column strip follow a similar pattern but remain negative.

\subsection{Membrane forces}

The X-direction membrane forces are shown in Figure 16 and can be compared with those from the ISO fire in Figure 10. It can be seen that for the parametric fire, the membrane forces continue to increase even after the fire temperature has decayed back to ambient. The greatest membrane forces are seen to occur along the column strip and at the end of the decay period these are about four times larger than at the start of the fire. These large membrane forces arise from the interaction between the edge beams, the columns and the displaced slab as the fire temperatures decay and the slab attempts to undergo thermal contraction at the same time as it regains strength and stiffness due to the decreasing temperatures. Well anchored continuous reinforcing steel in the slab is necessary to resist these large membrane forces.

\subsection{Horizontal displacements}

Figure 17 shows a comparison of the $\mathrm{X}$-direction displacements at point $\mathrm{A} 2$ for the analyses with and without a decay phase. The X-direction deflections at points B2, B4, D2 and D4 are shown in Figure 18. Once the fire goes out at 60 minutes, the deflections reduce considerably at the edge columns and corner columns. For the edge column at point B4, the tension in the column strip of the slab causes movement towards the centreline of the slabs. The deflection of the corner column at point D4 is influenced by the axial and lateral stiffnesses of the two edge beams and the change in thermal gradients once the fire goes out, together with the contraction of the slab as it cools.

\section{Discussions}

While the analysis could not investigate the shear performance of the flat slab floor, it is possible to get some idea of how the punching shear strength of the slab around the columns varies by looking at the variations in floor load transmitted to the columns during the fire exposure, as shown in Figure 19. Some of the load into the exterior and corner columns comes directly from the adjacent slab and some directly from the beams. For the interior columns, all the variation in load comes from interaction with the surrounding slab as the bending moments, membrane forces, and deflections change with time. The punching shear stresses at the column face and at a distance of half the slab depth from the column faces are shown in Figure 20.

It can be seen that at a distance of half-depth from the column face (which is the critical section used for punching shear calculations in design codes) the shear stress at ambient temperature is $1.6 \mathrm{MPa}$ and it increases to $1.7 \mathrm{MPa}$ at the end of the fire. At ambient temperature, New Zealand Concrete Structures Standard [22] specifies that "the maximum nominal shear stress for punching shear, on any part of the perimeter shall not exceed $0.5 \sqrt{ } \mathrm{f}_{\mathrm{c}}{ }^{\prime}$, , which gives a punching shear resistance of $2.74 \mathrm{MPa}$. Although it is clear that the punching shear will not cause a failure in this case at the ambient 
temperature, it is not possible at present to determine how the shear strength of the slab will deteriorate with increase in temperature and hence at what stage the material shear strength will fall below the required load resistance.

Moreover, all analytical models have inherent uncertainties and SAFIR is no exception. The analytically predicted response is pegged with the assumptions made in the modelling and actual behaviour may differ slightly. Nevertheless, as full-scale experimental investigations on structural fire behaviour are difficult and resource consuming, analytical investigations using finite element codes are the most common method adopted by the designers in predicting fire response of structures to be designed. In this context, it will be fair to say that designers must interpret the analytical results presented in this paper in relation to the assumptions made in the analytical modelling.

\section{Conclusions}

The analysis of a nine-bay flat slab exposed to fire has found that for the fires:

- The concrete and the reinforcing steel near the bottom of the slab heat up well before the top reinforcing steel and the top of the concrete. The resulting thermal gradient through the slab attempts to cause thermal bowing which cannot occur due to boundary conditions, leading to major redistribution of bending moments.

- Once the bottom steel temperature exceeds $300^{\circ} \mathrm{C}$, the yield strength of the steel decreases with increasing temperature, so that the negative (sagging) bending strength of the concrete section diminishes, as does its membrane strength.

For a fire without a decay phase:

- The bending moments in the slab reach a peak when the bottom steel reaches 300$400^{\circ} \mathrm{C}$ and the slab loses strength as the bars heat up further.

- The tensile membrane forces are limited by the loss of strength in the reinforcing bars as they heat up, and by increasing vertical deflections.

- No failure occurred, even after four hours of fire exposure, due to the beneficial effects of large displacements and tensile membrane action.

For a fire with a decay phase, the slab behaves differently in the following ways:

- The bottom of the concrete slab starts to cool once the temperatures start to drop, so that the yield strength of the bottom reinforcing increases and it starts to contract, along with the lower part of the slab.

- Vertical deflections stop increasing after the fire goes out.

- The average bending moments in the slab change from positive to negative as the slab cools down and the thermal gradients diminish.

- The membrane forces become tensile and keep increasing long after the fire goes out, due to increasing strength and continuing thermal contraction. These membrane forces become much greater than those predicted during the continuous four hours of fire exposure. Therefore, designers must ensure good anchorage of all slab reinforcing, especially the top steel, into the edge beams to resist the tensile membrane forces. 


\section{References}

[1] Buchanan, A.H. (2001). "Structural Design for Fire Safety". Wiley, Chichester, England; New York.

[2] Selvaggio, S.L. and Carlson, C.C. (1963). "Effect of restraint on fire resistance of prestressed concrete", American Society for Testing and Materials, STP 344.

[3] Issen, L.A., Gustaferro, A.H. and Carlson, C.C. (1970). "Fire tests of concrete members; An improved method for estimating thermal restraint forces", Fire Test Performance, pp.153-185.

[4] Anderberg, Y. (1983). "Properties of materials at high temperatures- Steel", RILEM Report, University of Lund, Sweden.

[5] Harmathy, T.Z. (1993). "Fire safety design and concrete", Longman Scientific \& Technical; Wiley, Harlow, Essex, England, New York, NY.

[6] Lim, L.C.S. (2003). "Membrane action in fire exposed concrete floor systems". Fire Engineering Research Report Number 03/2, University of Canterbury, Christchurch, New Zealand.

[7] Park, R. (1964). "Tensile membrane behaviour of uniformly loaded rectangular reinforced concrete slabs with fully restrained edges", Magazine of Concrete Research, vol. 16, no. 46, pp. 39-44.

[8] Park, R. and Gamble, W. L. (2000). "Reinforced concrete slabs", 2nd Ed., Wiley, New York.

[9] Bailey, C.G. and Moore, D.B. (2000a). "The structural behaviour of steel frames with composite floor slabs subject to fire: Part 1: Theory", The Structural Engineer, vol. 78, no. 11, pp. 19-27.

[10] Bailey, C.G. and Moore, D.B. (2000b). "The structural behaviour of steel frames with composite floor slabs subject to fire: Part 2: Design", The Structural Engineer, vol. 78, no. 11, pp. 28-33.

[11] Bailey, C.G. (2001). "Membrane action of unrestrained lightly reinforced concrete slabs at large displacements", Engineering Structures, vol. 23, no. 5, pp. 470-483.

[12] Bailey, C.G. (2004). "Membrane action of slab/beam composite floor systems in fire", Engineering Structures, vol.26, no.12, pp.1691-1703.

[13] Franssen, J.M., Kodur, V.K.R. and Mason, J. (2002). "User's manual for SAFIR 2001: A computer program for analysis of structures at elevated temperature conditions", University of Liege, Department Structures de Genie Civil, Service Ponts et Charpentes, Belgium.

[14] ACI (1992). "Building code requirements for reinforced concrete" (ACI 318) (revised 1992) and commentary (ACI 318R-89) (revised 1992), American Concrete Institute, Detroit, Mich., USA.

[15] Wang, G. (2004). "Performance of reinforced concrete flat slabs exposed to fire", Fire Engineering Research Report Number 06/2, University of Canterbury, Christchurch, New Zealand. http://www.civil.canterbury.ac.nz/fire/fe resrch reps.shtml

[16] NZS 4203 (1992). "Code of practice for general structural design and design loadings for buildings", Standards New Zealand, Wellington.

[17] AS/NZS 1170.0 (2002). "Structural design actions, Part 0: General principles", Standards Australia/Standards New Zealand.

[18] ISO (1975). "Fire resistance tests - elements of building construction", ISO 8341975, International Organization for Standardization. 
[19] EC2 (2002). "Eurocode 2: Design of concrete structures, prEN 1992-1-2, General rules- structural fire design", European Committee for Standardization, Brussels.

[20] Lim, L., Buchanan, A., Moss, P., and Franssen, J-M. (2004). "Numerical modelling of two-way reinforced concrete slabs in fire", Engineering Structures, vol. 26, pp. 1081-1091.

[21] Talamona, D. and Franssen, J-M. (2002-2003). "Nonlinear thin shell finite element for steel and concrete structures subjected to fire: theoretical development", J. Applied Fire Science, vol. 11, no. 4, pp. 291-310.

[22] NZS 3101 (2006). "Concrete Structures Standards", Standards New Zealand, Wellington. 


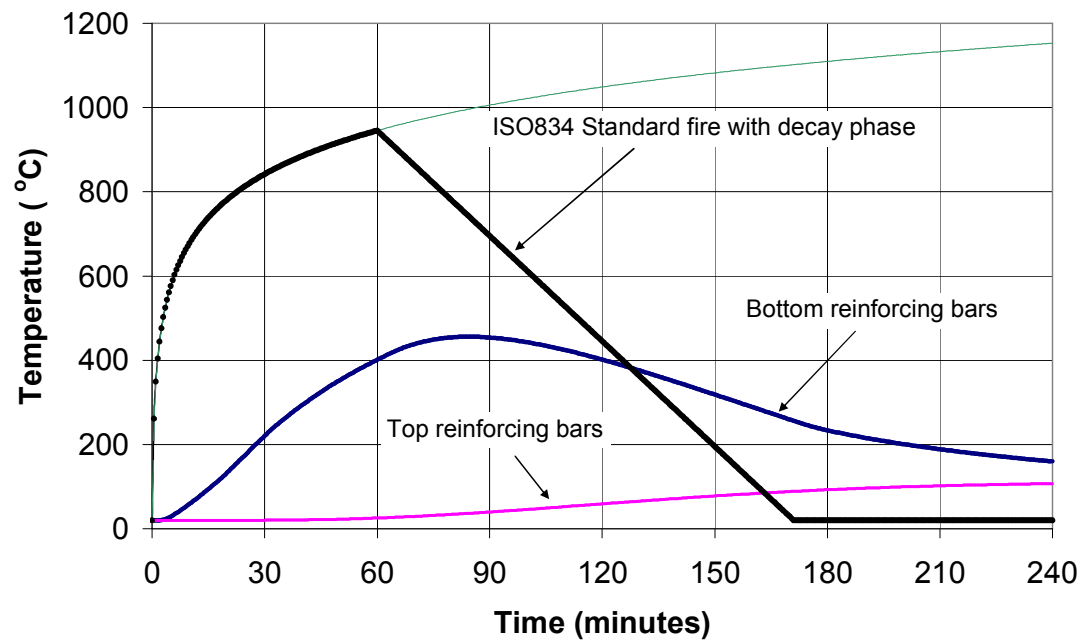

Figure 1. ISO 834 standard fire curve with a decay phase after 60 minutes, and the resulting temperatures in top and bottom reinforcing bars. 

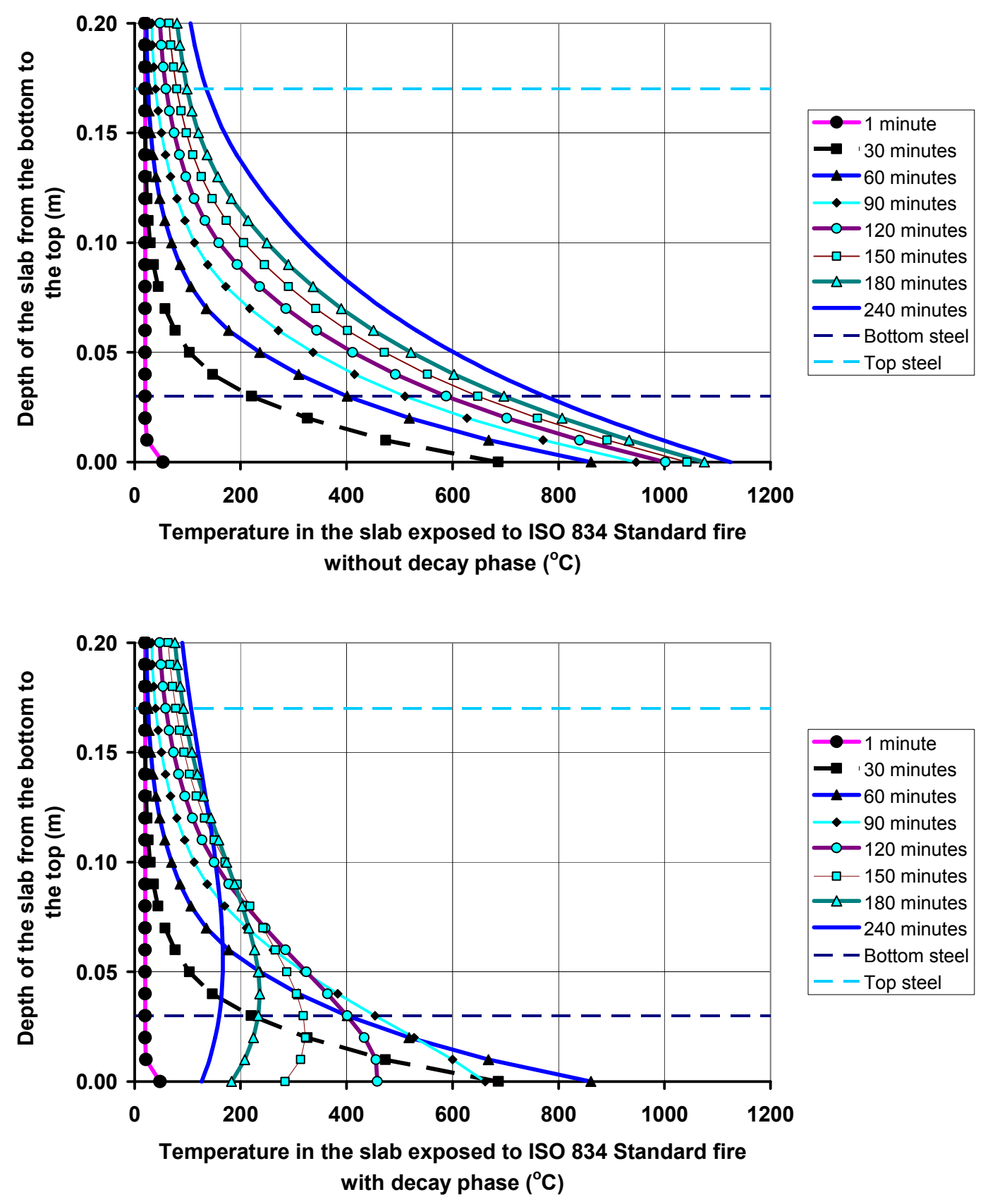

Figure 2. Distribution of temperatures in the slabs exposed to an ISO 834 standard fire without a decay phase (top) and with a decay phase(bottom). 


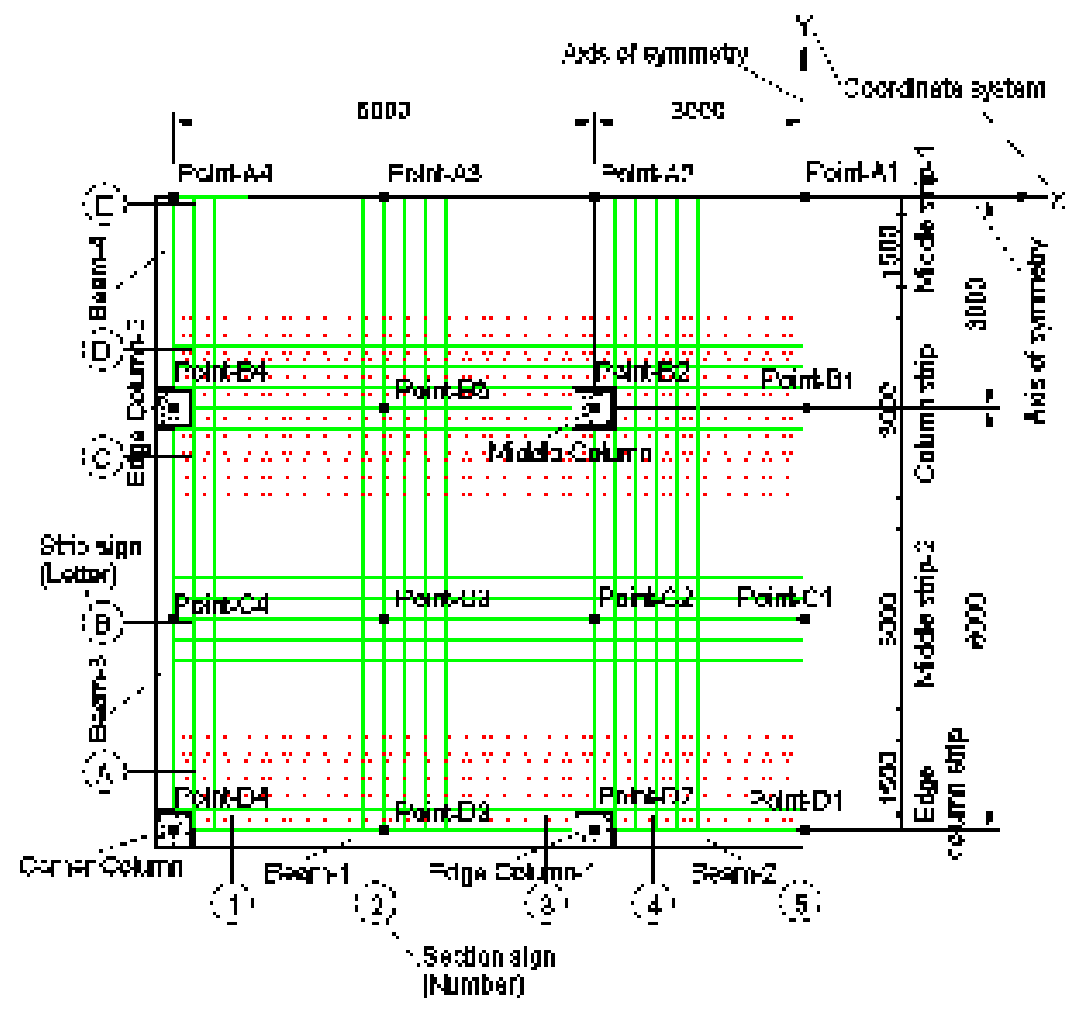

Figure 3. Reference diagram for the nine-bay flat slab (showing one quarter of the slab) 


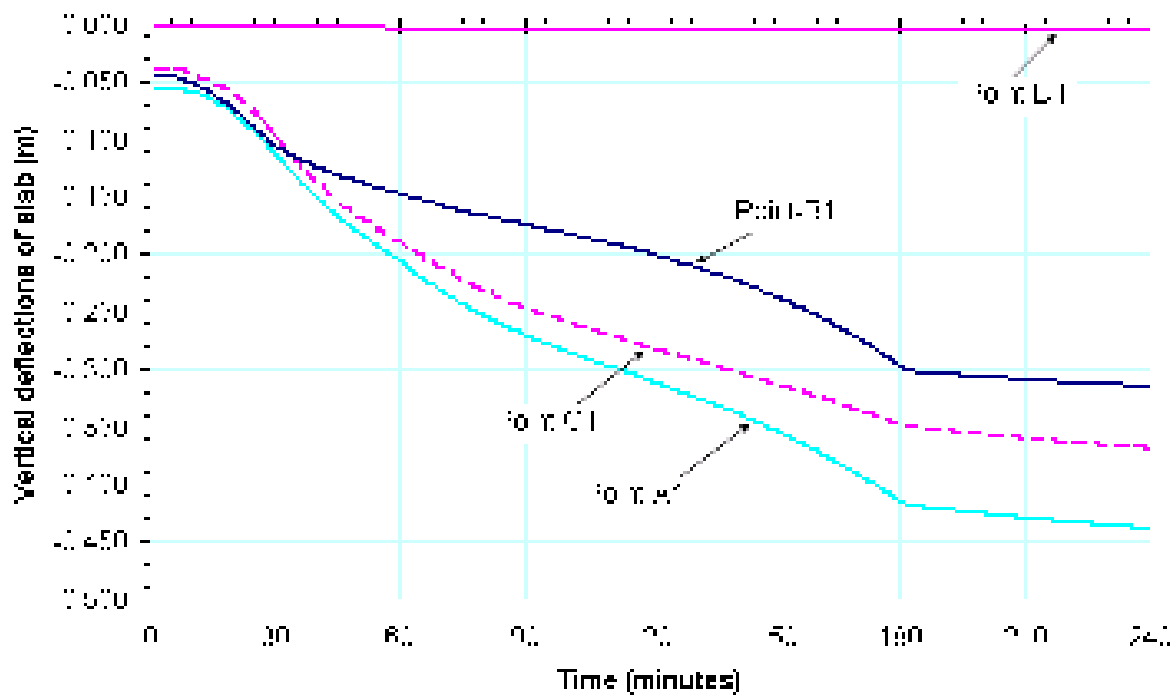

Figure 4. Vertical deflections of the slab at points A1, B1, C1 and D1.

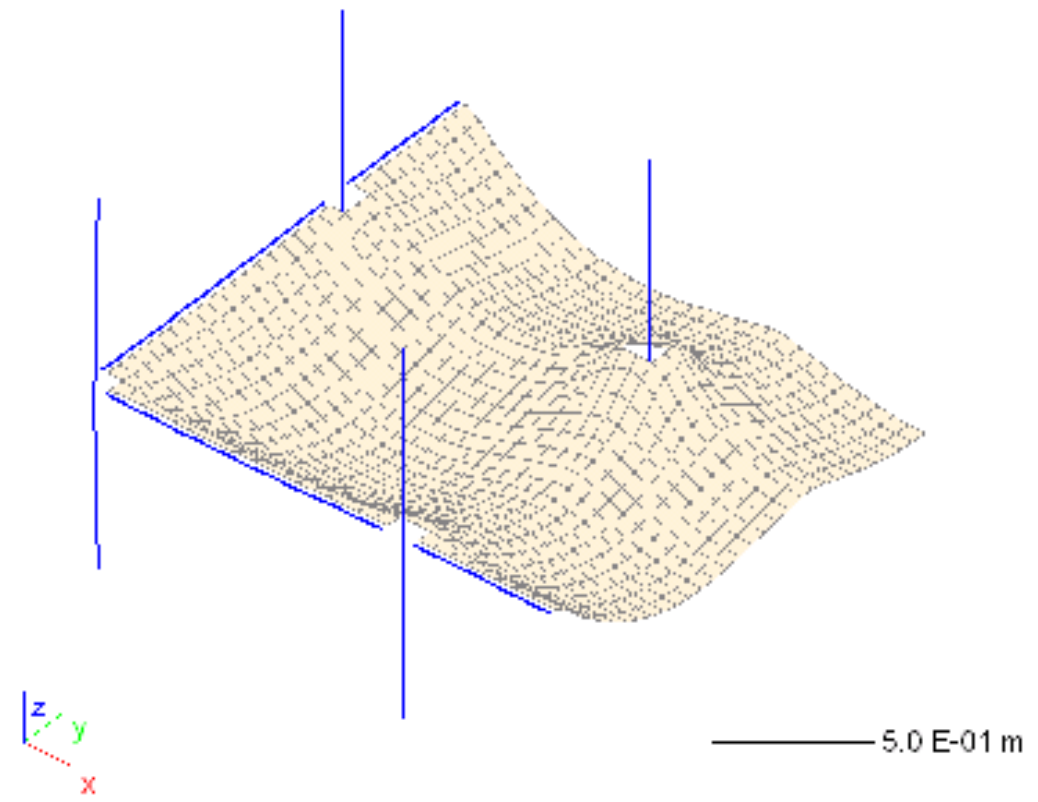

Figure 5. Vertical deflected shape of the slab at 180 minutes, scale factor $=5$. 


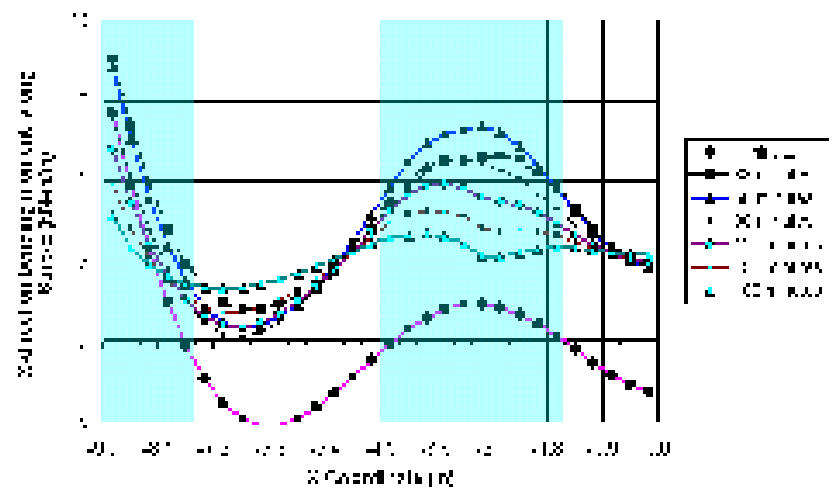

Figure 6. X-direction bending moments along Strip E during ISO 834 fire exposure.

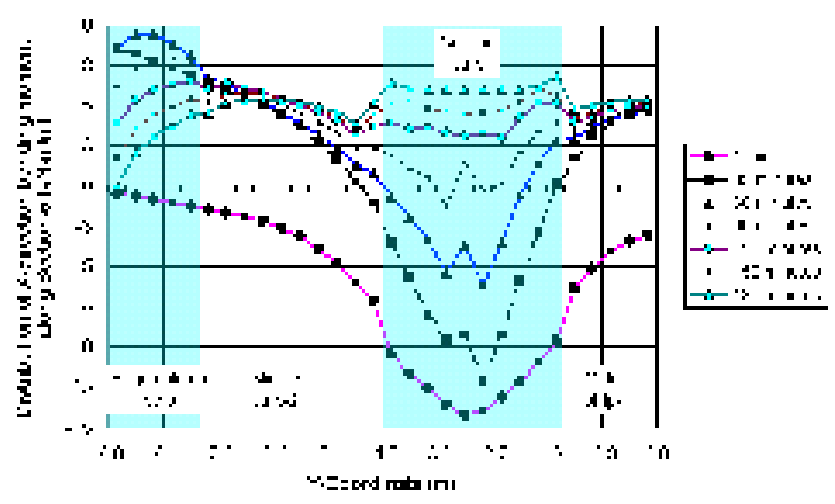

Figure 7. Distribution of X-direction bending moments along Section 5

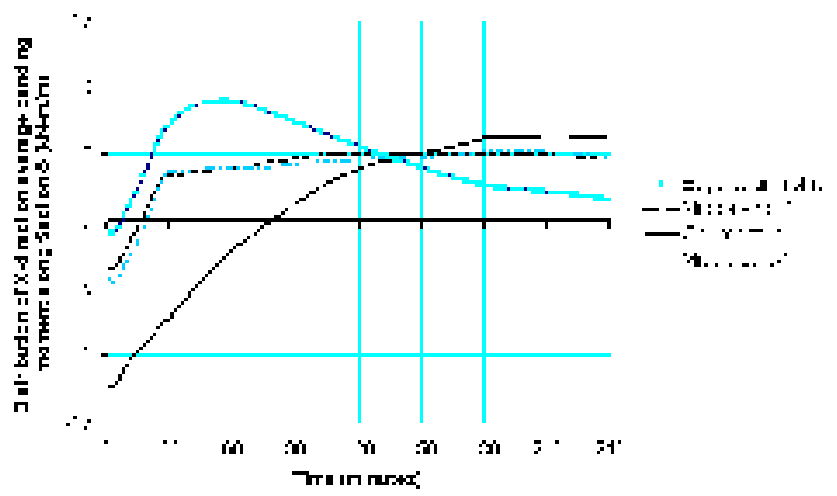

Figure $8 . X$-direction average bending moments in the strips along Section 5 


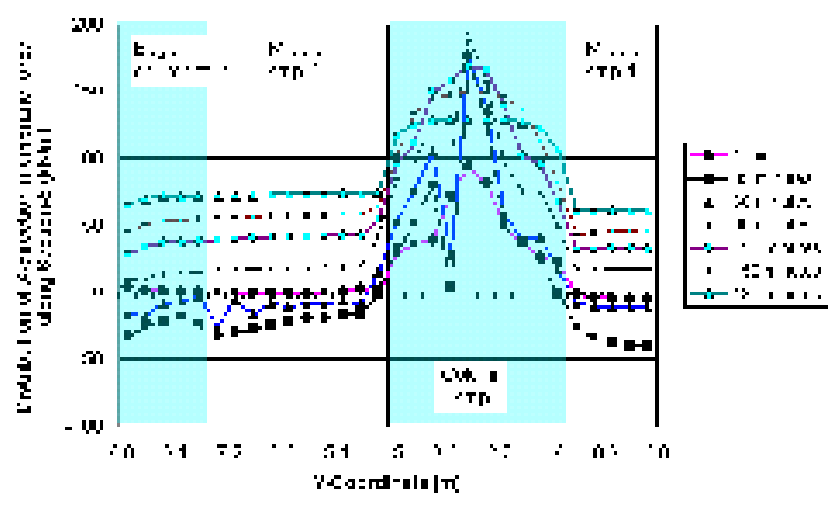

Figure 9. Distribution of X-direction membrane forces along Section 5

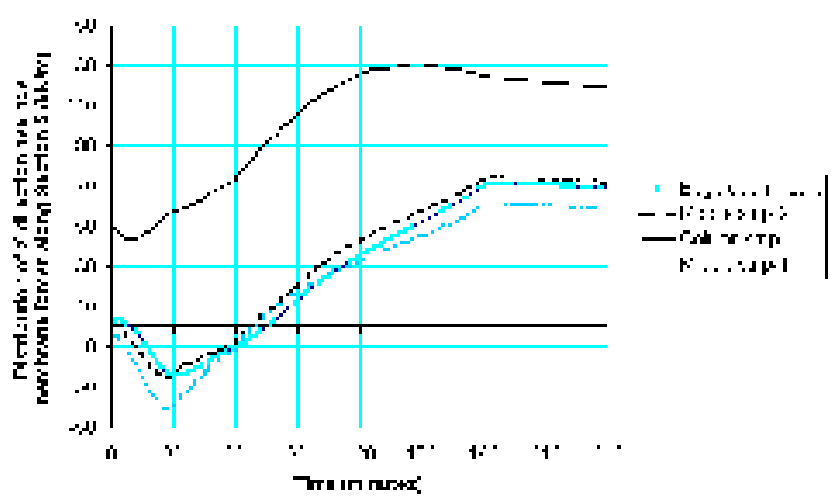

Figure 10. $\mathrm{X}$-direction membrane forces in the strips along Section 5 


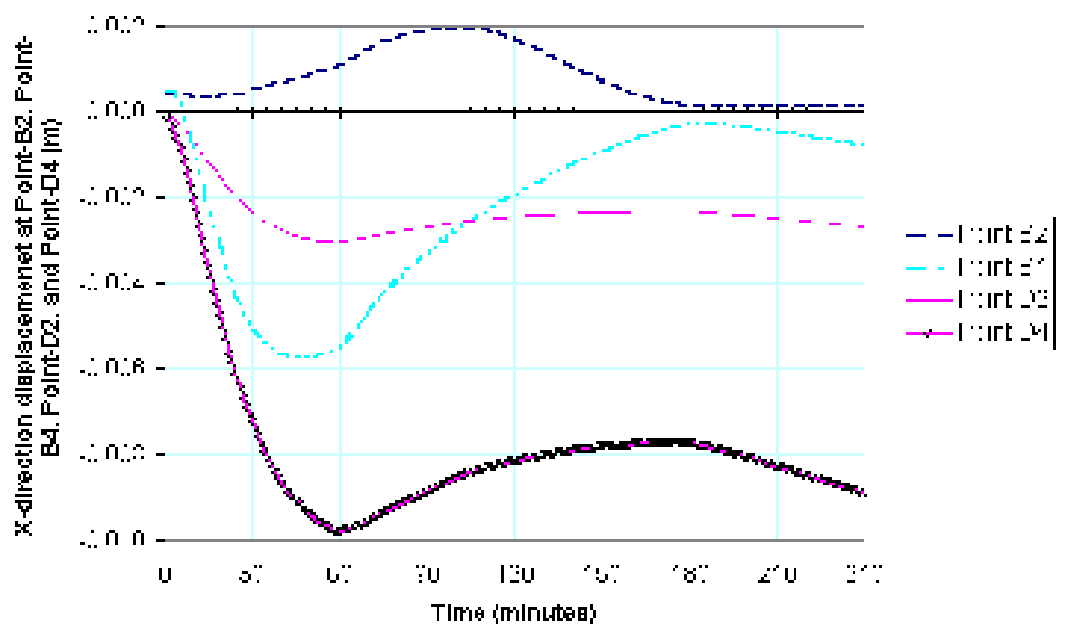

Figure 11. X-direction displacements at points B2, B4, D2 and D4.

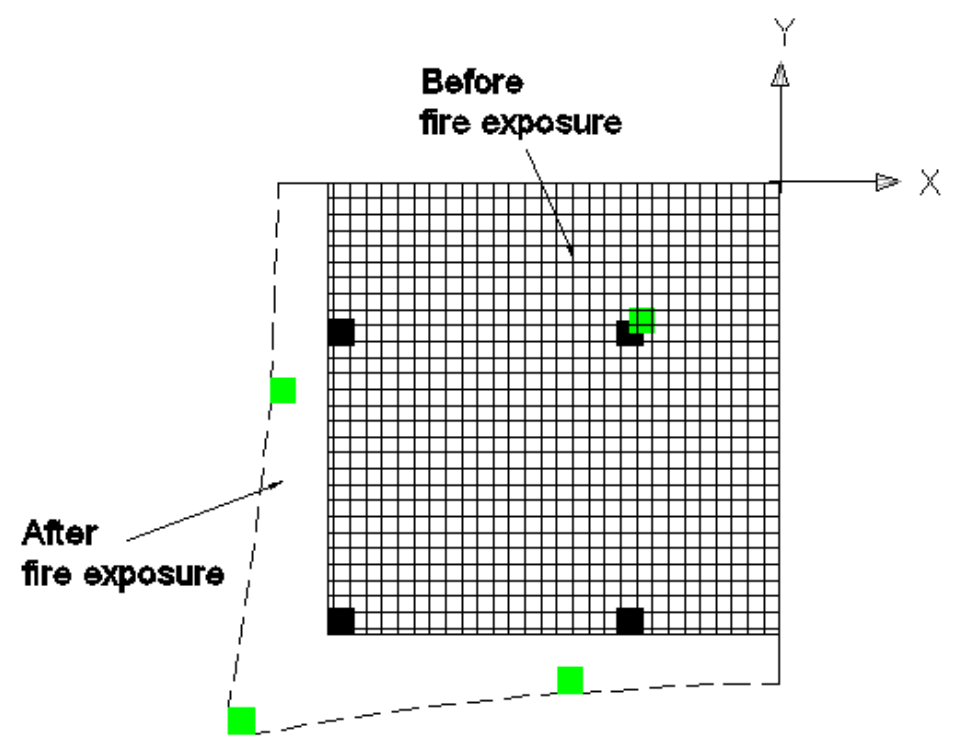

Figure 12. Shape of the slab before the fire, and outline after 120 minutes of fire exposure (not to scale). 


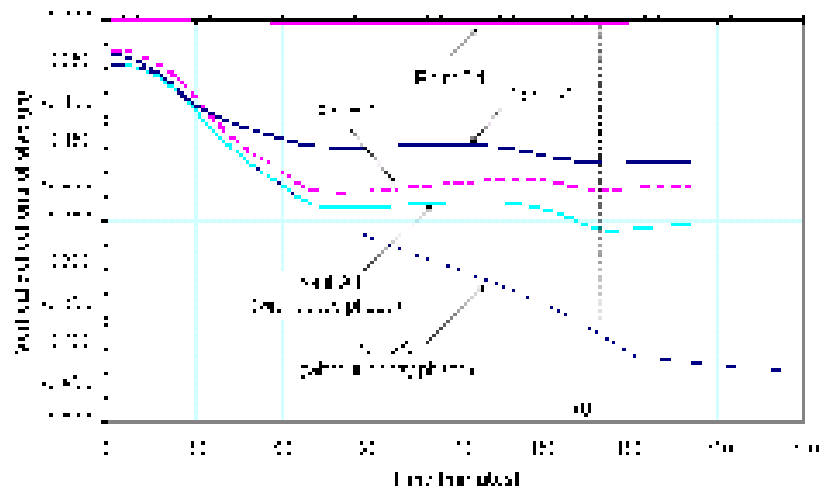

Figure 13. Fire with decay phase. Vertical deflections of the slab at points A1, B1, $\mathrm{C} 1$ and D1.

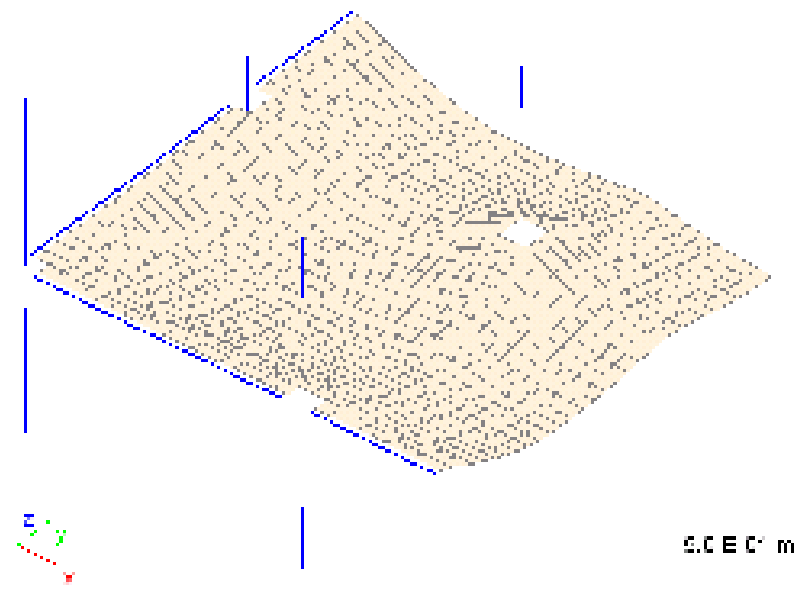

Figure 14. Fire with decay phase. Vertical deflected shape of the slab at 180 minutes, scale factor $=5$. 


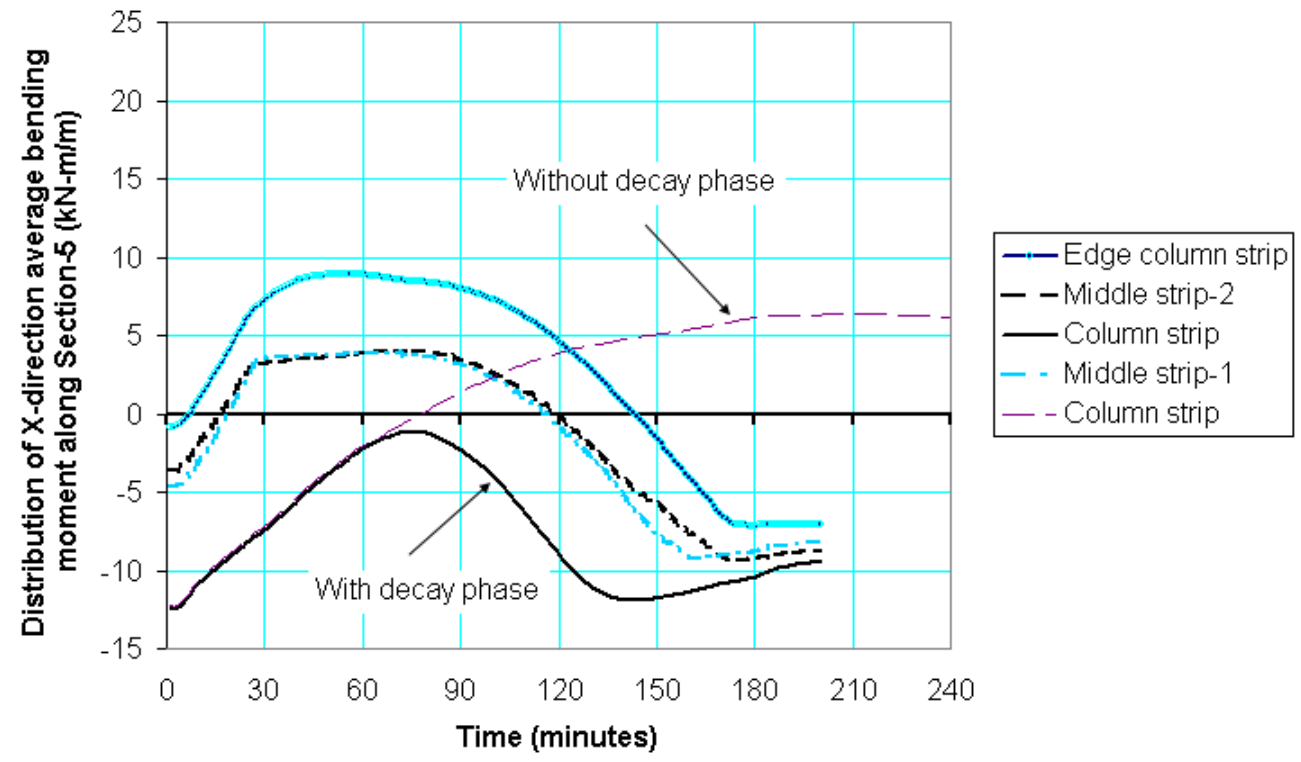

Figure 15. Fire with decay phase. X-direction average bending moments in the strips along Section 5.

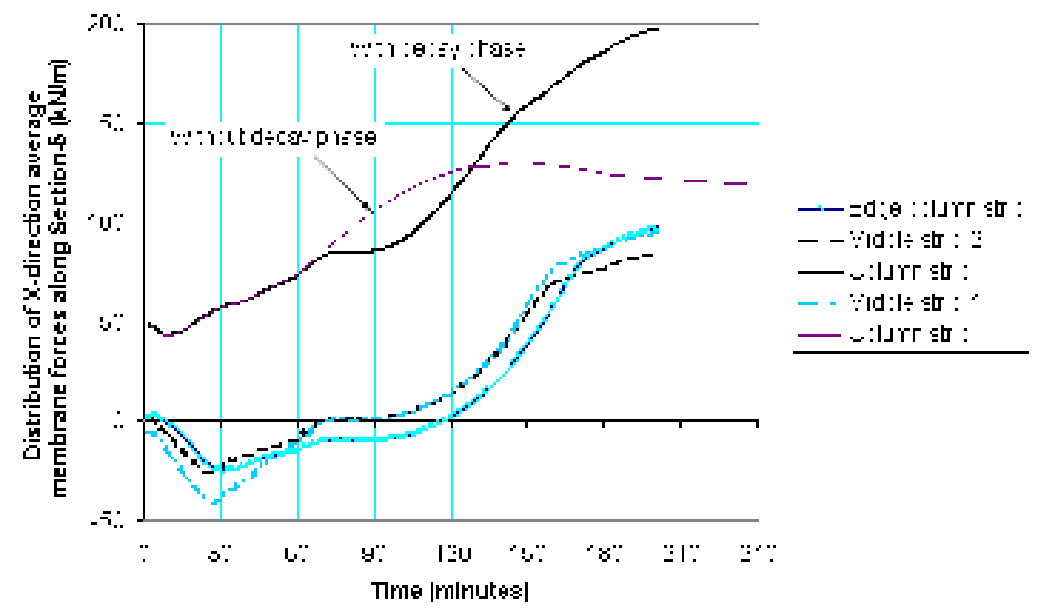

Figure 16. Fire with decay phase. X-direction average membrane forces in the strips along Section 5. 


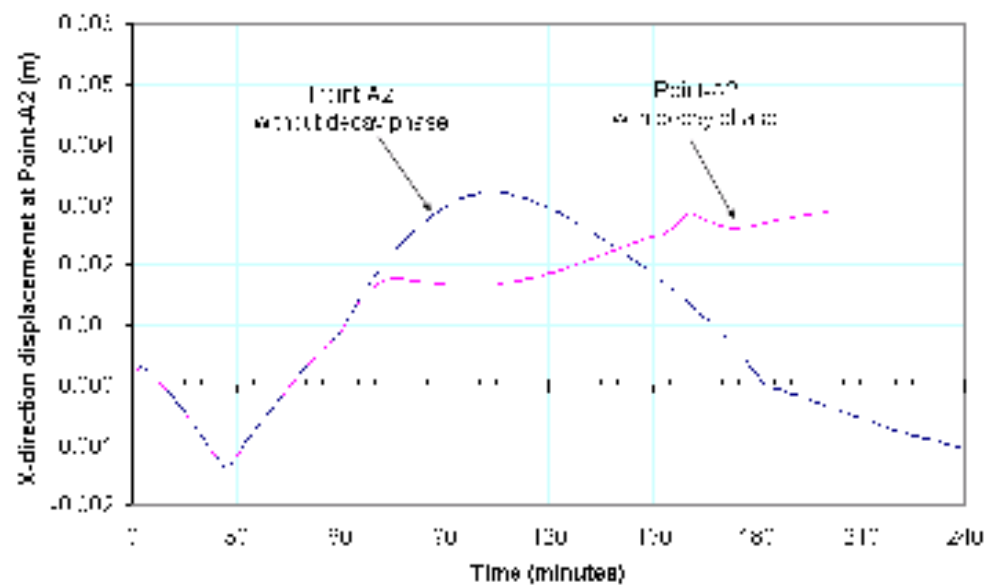

Figure 17. Comparison of $\mathrm{X}$-direction displacements at point $\mathrm{A} 2$ for both fires.

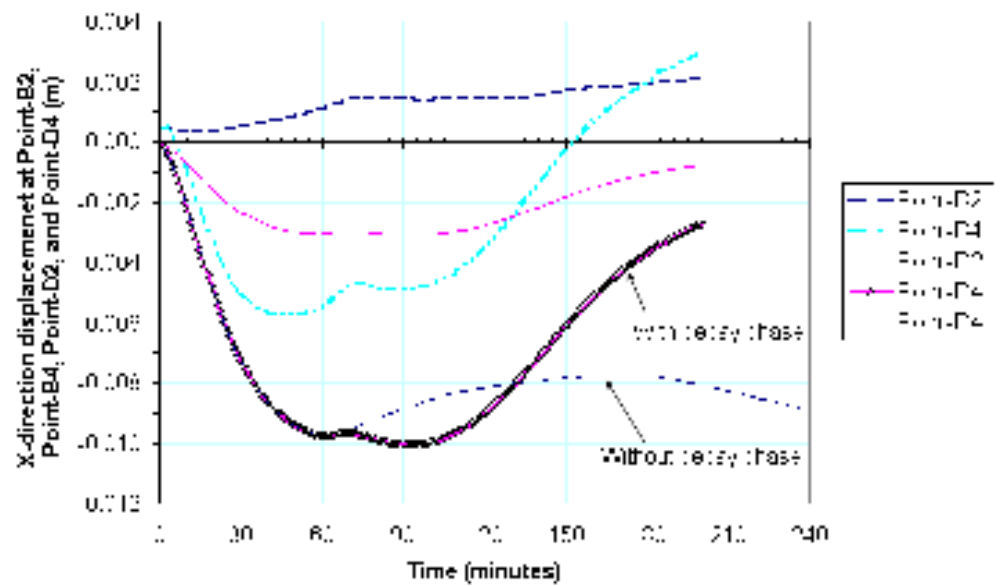

Figure 18. Fire with decay phase. X-direction displacements at points B2, B4, D2 and D4. 


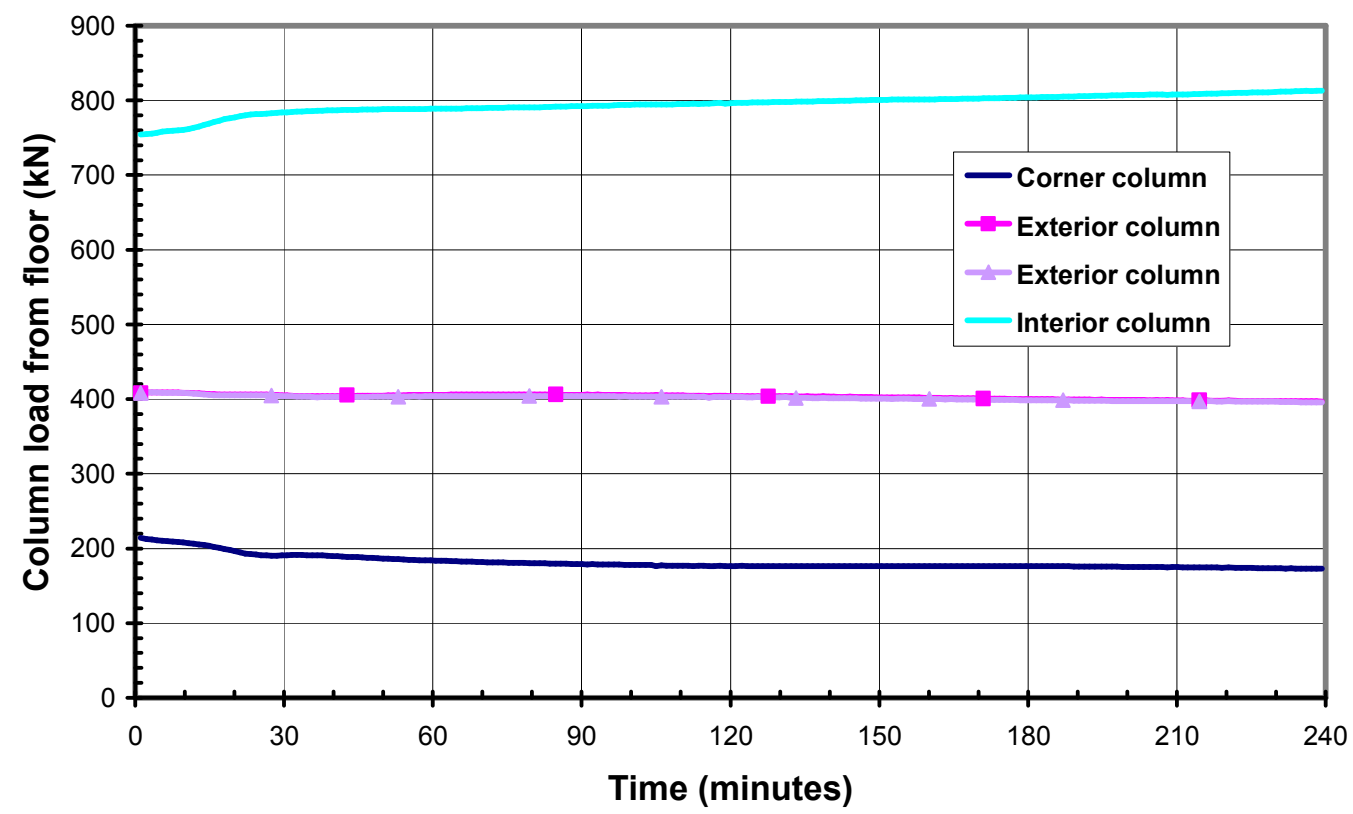

Figure 19. Distribution of floor loads to the columns for a fire without decay

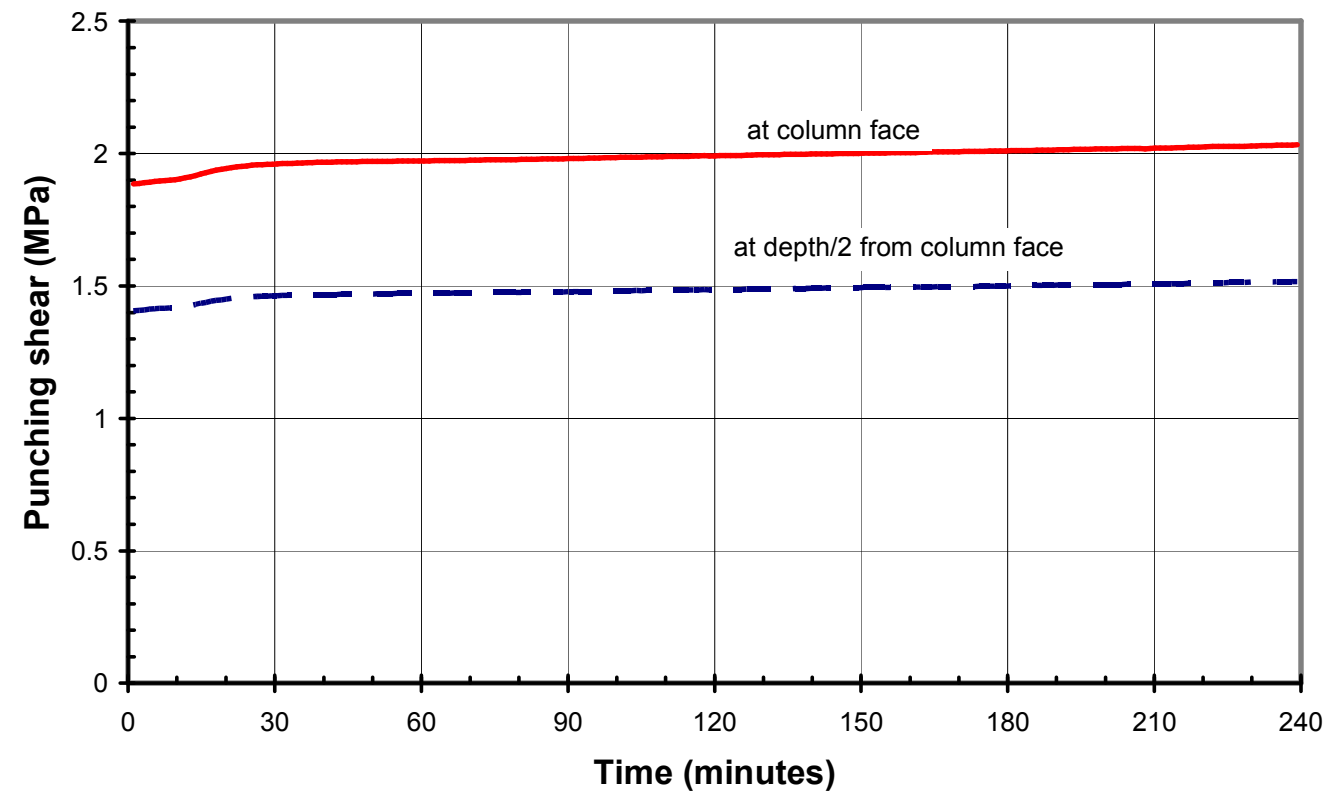

Figure 20. Punching shear stress at the interior columns for a fire without decay 